\title{
Assessing socioeconomic status in adolescents: the validity of a home affluence scale
}

\author{
J Wardle, K Robb, F Johnson
}

J Epidemiol Community Health 2002;56:595-599

See end of article for authors' affiliations

......................

Correspondence: Professor J Wardle, Imperial Cancer Research Fund Health

Behaviour Unit, Department of Epidemiology and Public Health, University College

London, Gower Street, London WCIE 6BT, UK; j.wardle@ucl.ac.uk

Accepted for publication 23 November 2001

\begin{abstract}
Study objective: To examine the completion rate, internal reliability, and external validity of a home affluence scale based on adolescents' reports of material circumstances in the home as a measure of family socioeconomic status.

Design: Cross sectional survey.

Setting: Data were collected from a school based study in seven schools in the north of England Cheshire over a five month period from September 1999 to January 2000.

Participants: 1824 students (1248 girls, 567 boys) aged 13-15 years who were attending normal classes in Years 9 and 10 in 7 schools on the days of data collection.

Main results: Comparatively poor completion rates were found for questions on parental education and occupation while material deprivation items had much higher completion rates. There was evidence that students with poorer material circumstances were less able to report parental education and occupation whereas material based questions showed less bias. A home affluence scale composed of material items was found to have adequate internal reliability and good external validity. Conclusions: A home affluence scale based on material markers provides a useful alternative in assessing family affluence in adolescents. Additionally, it prevents exclusion of those less materially well off adolescents who fail to complete conventional socioeconomic status items.
\end{abstract}

$\mathrm{R}$ esearch on the development of health behaviours during adolescence has highlighted the need to take account of socioeconomic status (SES), in order to investigate the emergence of socioeconomic disparities in health behaviour. $^{12}$

In adult populations, SES is usually derived from information on occupation, education, or income, ${ }^{3}$ but these kinds of data pose a problem when the respondent population is adolescents who are being asked to report on their parents' characteristics. Studies that have made use of adolescents' reports of their parents income, occupation, and education have reported high levels of missing or invalid data. A study from the Netherlands ${ }^{2}$ found that among $15-16$ year olds $11 \%$ were unable to provide details of paternal occupation and $27 \%$ failed to record maternal occupation. Paternal education was also missing for $16 \%$ of participants, with $12 \%$ missing maternal education. Goodman ${ }^{5}$ reported a completion rate of only 83\% for resident parents' occupation in a sample of 20745 young people aged 11-21 years in the United States. A recent Norwegian study of 13 and 15 year olds, found that non-response rates for parental occupation and education questions ranged from $11 \%-16 \% .{ }^{6}$ The use of individual interviews has been shown to produce more detailed and informative responses, ${ }^{7}$ but the incorporation of interviews into the study protocol adds considerably to the complexity of data collection and processing, and may be prohibitive in many studies.

In studies where written responses are used, poor completion rates for SES items inevitably limit the number of cases available for analysis, and compromise the power of the study. Even more seriously, there may be a bias in the missing data, with higher levels of non-response among children from more socioeconomically deprived backgrounds, where issues of employment or education are discussed less.

One approach is to utilise other information on household circumstances as a basis for deriving SES. There has been an increasing use of material indicators of socioeconomic deprivation, such as car ownership and housing tenure, in adult surveys. ${ }^{8-10}$ In adolescents, a great advantage of simple questions on material circumstances (for example, "does your family own a car?") is that the adolescent will almost certainly know the answers. Currie et al ${ }^{11}$ found that $98 \%$ of $11-15$ year olds could give information on car ownership, telephones in the home, and whether or not they shared a bedroom, compared with only $89 \%$ being able to report paternal occupation, and $78 \%$ providing data codeable for paternal social class. They created a composite scale by adding the three material indicators to form a "family affluence scale" (FAS). Using data from the children who were able to report on parental occupation, they found a consistent association between FAS score and parental social class, which provided some confirmation of the validity of the scale.

The aim of this study was to investigate the completion of traditional measures of SES compared with material indicators of home affluence, and to determine levels of socioeconomic bias in response rates. Internal reliability of a home affluence scale (HASC) composed of material indicators was also examined. External validity of the HASC was tested against parental education, occupation, and markers of area level deprivation.

\section{METHODS}

The data come from a 1999 school based survey of 1824 adolescents aged 13-15 years. The survey examined a range of health behaviours in adolescence with a particular focus on weight and weight control, for which reason the sample was predominantly girls. The sampling frame comprised eight girls' secondary schools and 31 mixed sex secondary schools in north west England. The percentage of pupils at the school eligible to receive the income linked benefit of free school

Abbreviations: SES, socioeconomic status; FAS, family affluence scale; HASC, home affluence scale 
Table 1 Item completion rates by school type and gender

\begin{tabular}{|c|c|c|c|c|c|c|}
\hline & \multicolumn{3}{|c|}{ School type } & \multirow[b]{2}{*}{ Total } & \multirow{2}{*}{$\begin{array}{l}\text { Significance of linear } \\
\text { trend for school type }\end{array}$} & \multirow{2}{*}{$\begin{array}{l}\text { Significance of gender } \\
\text { differences }\end{array}$} \\
\hline & High SES & Middle SES & Low SES & & & \\
\hline \multicolumn{7}{|l|}{$\mathrm{N}$} \\
\hline Boys & 199 & 162 & 215 & 576 & & \\
\hline Girls & 388 & 467 & 393 & 1248 & & \\
\hline \multicolumn{7}{|c|}{ Father's occupation able to be coded } \\
\hline Boys & $59.8 \%$ & $48.8 \%$ & $44.7 \%$ & $51.0 \%$ & $\chi^{2}[1]=9.38 p=0.00$ & \\
\hline Girls & $69.1 \%$ & $53.3 \%$ & $46.8 \%$ & $56.2 \%$ & $\chi^{2}[1]=39.16 p=0.00$ & $\chi^{2}[1]=3.90 p=0.05$ \\
\hline \multicolumn{7}{|c|}{ Mother's occupation able to be coded } \\
\hline Boys & $58.8 \%$ & $53.8 \%$ & $39.5 \%$ & $50.2 \%$ & $\chi^{2}[1]=15.47 p=0.00$ & \\
\hline Girls & $66.0 \%$ & $59.5 \%$ & $47.8 \%$ & $57.9 \%$ & $\chi^{2}[1]=26.37 p=0.00$ & $\chi^{2}[1]=9.40 p=0.00$ \\
\hline \multicolumn{7}{|c|}{ Parents' college attendance completed } \\
\hline Boys & $82.9 \%$ & $69.4 \%$ & $70.2 \%$ & $74.5 \%$ & $\chi^{2}[1]=8.50 p=0.00$ & \\
\hline Girls & $85.8 \%$ & $73.4 \%$ & $67.2 \%$ & $75.3 \%$ & $\chi^{2}[1]=36.44 p=0.00$ & $\chi^{2}[1]=0.15 p=0.37$ \\
\hline \multicolumn{7}{|c|}{ Postcode completed } \\
\hline Boys & $94.5 \%$ & $88.8 \%$ & $70.2 \%$ & $83.5 \%$ & $\chi^{2}[1]=45.18 p=0.00$ & \\
\hline Girls & $99.0 \%$ & $91.0 \%$ & $83.7 \%$ & $91.2 \%$ & $\chi^{2}[1]=56.47 p=0.00$ & $\chi^{2}[1]=23.28 p=0.00$ \\
\hline \multicolumn{7}{|c|}{ Housing tenure completed } \\
\hline Boys & $95.0 \%$ & $89.4 \%$ & $89.8 \%$ & $91.5 \%$ & $\chi^{2}[1]=3.49 p=0.06$ & \\
\hline Girls & $94.6 \%$ & $93.4 \%$ & $88.0 \%$ & $92.1 \%$ & $\chi^{2}[1]=11.48 p=0.00$ & $\chi^{2}[1]=0.17 p=0.37$ \\
\hline \multicolumn{7}{|c|}{ Car ownership completed } \\
\hline Boys & $98.5 \%$ & $93.8 \%$ & $98.6 \%$ & $97.2 \%$ & $\chi^{2}[1]=0.02 p=0.89$ & \\
\hline Girls & $99.5 \%$ & $99.4 \%$ & $99.5 \%$ & $99.4 \%$ & $\chi^{2}[1]=0.00 p=0.99$ & $\chi^{2}[1]=15.56 p=0.00$ \\
\hline \multicolumn{7}{|c|}{ Free school meals completed } \\
\hline Boys & $98.0 \%$ & $92.5 \%$ & $98.1 \%$ & $96.5 \%$ & $\chi^{2}[1]=0.02 p=0.88$ & \\
\hline Girls & $97.2 \%$ & $98.9 \%$ & $99.0 \%$ & $98.4 \%$ & $\chi^{2}[1]=4.07 p=0.04$ & $\chi^{2}[1]=6.42 p=0.01$ \\
\hline \multicolumn{7}{|c|}{ Computer ownership completed } \\
\hline Boys & $99.0 \%$ & $93.1 \%$ & $98.6 \%$ & $97.2 \%$ & $\chi^{2}[1]=0.03 p=0.87$ & \\
\hline Girls & $99.5 \%$ & $99.6 \%$ & $99.5 \%$ & $99.5 \%$ & $\chi^{2}[1]=0.00 p=0.99$ & $\chi^{2}[1]=17.45 p=0.00$ \\
\hline
\end{tabular}

meals was used as a rough indicator of school level social deprivation, and schools were classified into high, medium, and low deprivation groups. A stratified sample of seven schools was selected to participate, one girls' school and one mixed school in the high and low deprivation groups, and two girls' schools and one mixed school in the intermediate group. The use of a stratified sample maximises the opportunity to compare completion rates across social background, but limits comparisons with studies using representative samples. All pupils in Years 9 and 10 who were attending school on the days of data collection, were eligible to participate. Pupils and their parents were informed about the study and given the opportunity to refuse participation. Only 1.2\% declined to take part.

Students completed a questionnaire in class, with the investigators present to provide assistance. The questionnaire included a number of items on demographic characteristics. Material indicators included: (a) housing tenure ("Thinking about the house you live in at the moment, do your parents own it or rent it? (If they have a mortgage tick 'they own it)"; response options were: they own it; they rent it; I don't know), (b) car ownership ("Do you have a car or van at home?"; response options: yes one car or van; yes more than one car or van; no we don't own a car or van), (c) ownership of a computer ("Do you have a home computer at home? (Do not include playstations or other computers that can only be used for games)"; response options: yes; no), and (4) option of free school meals ("Do you yourself have the option of free lunchtime meals at school?", response options: yes; no). Number of telephones in the home, an item that has been used in previous work, ${ }^{11}$ was not included because of the huge expansion of mobile phone ownership in the UK. Whether the adolescent had their own bedroom has also been used in some studies, ${ }^{11}$ but was left out after advice from the schools that adolescents may find this question intrusive. A simple measure of parental education asked "Did your parents go to college or university after leaving school?" (response options: yes both of them; yes one of them; no neither of them; don't know). Paternal employment and occupation (with fathers including stepfathers) was asked of all students who responded that their father (or stepfather) lived with them most of the time: "Does your father (or stepfather if you live with him) have a paid job?" (response options: yes; no). If yes: "What is his job?" Free responses were given to this question, which were coded using the registrar general's Classification of Occupations. ${ }^{12}$ The same question was then asked for mothers (or stepmothers). Lastly, the students were asked to give their postcode ("Please write your postcode at home, if you know it"). Postcode information was linked to small area statistics from the 1991 census. $^{13}$ The information for each census enumeration district (based on an average of around 460 residents), includes several indicators of socioeconomic deprivation. In this study we utilised the Townsend Material Deprivation Index,${ }^{14}$ which incorporates unemployment, overcrowding, non-car ownership, and non-home ownership.

Results were analysed using SPSS (Version 8.0) using $\chi^{2}$ and logistic regression to compare completion rate differences across gender, school type, and family affluence scores. Pearson and Spearman correlations were used to assess the association between the individual material indicators with the total HASC score and to consider the relation between the HASC and traditional measures of SES.

\section{RESULTS}

The sample comprised 1824 students (1248 girls, 576 boys) who were on average age 14.4 years old. Most of them described themselves as white $(91 \%)$, with $0.5 \%$ black, $0.5 \%$ Asian, 5\% mixed race, and $1 \%$ other. Two per cent did not complete the ethnicity item. This ethnic distribution is reasonably representative of the geographical area from which the schools were recruited.

The lowest completion rates were for the questions on parental employment. Twenty two per cent of participants did not live with a father or stepfather, so paternal information was not asked for. Six per cent did not live with a mother or stepmother. An additional $7 \%$ of fathers and $22 \%$ of mothers were not in paid employment at the time. A further $16 \%$ of participants gave answers to the paternal occupation question that provided insufficient information to code paternal social 
Table 2 Correlations between individual material indicators and with the total score (all significant at $p<0.01$ )

\begin{tabular}{lllll}
\hline & Tenure & Computer & Free school meals & Total HASC \\
\hline Car $(0,1,2)$ & 0.29 & 0.33 & 0.26 & 0.76 \\
Tenure $(0,1)$ & - & 0.19 & 0.25 & 0.56 \\
Computer $(0,1)$ & & - & 0.17 & 0.56 \\
Free school meals $(0,1)$ & & - & 0.62 \\
\hline
\end{tabular}

class (for example, "He works at Cadbury's") or failed to give a description. Similarly 16\% of information on mothers' occupation was uncodeable or missing. Overall this meant that family SES could be derived from information on parental occupation for fewer than $60 \%$ of students. The education questions were better completed, but still, one in four participants responded that they didn't know whether their parents had a college education. Inability to respond to this question was associated with parental absence $\left(\chi^{2}[1]=16.2, p=0.00\right)$ but even among those who lived with both parents, $22 \%$ could not respond to this question. Postcodes, used to derive area level data, were reported by almost $90 \%$ of participants. The material indicators were all completed by more than $90 \%$ of the participants, with car and computer ownership having extremely high completion rates.

Completion rates were examined by age group but no significant differences were found between the children in year 10 (average age 14.9 years) and those in Year 9 (average age 13.9 years). Girls had higher completion rates than boys, with most of the gender differences being significant.

To examine the question of differential completion in relation to SES, completion rates were examined at the school level. Less affluent schools had significantly poorer completion rates for parental education, paternal and maternal occupation, and postcode. Of the material indicators, only housing tenure was completed less successfully by the pupils from less affluent backgrounds, while free school meals showed an inverse gradient for girls, such that girls from the more affluent schools were less likely to provide a response. The other material measures, car ownership, and computers, showed no significant gradient across the three school types. Completion rate by gender and school type are shown in table 1 .

The four material indicators were then combined to form the HASC, by adding a point for each of the following: the family owning a car, owning two cars, the family owning the home, the family owning a computer, and the pupil not having the option of free school meals. This generated a scale with possible scores ranging from $0-5$. Intercorrelations between the items were all modest but statistically significant (see table 2). The Cronbach's $\alpha$ of the final scale was moderate $(\alpha=0.55)$.

To assess the external validity of the scale, we examined associations with occupational social class and parental education where these were available. Associations with parental occupation are shown in table 3, where the three groups with the lowest affluence scores have been combined to produce a more even distribution with roughly equal numbers of participants in each group. HASC scores were modestly correlated with paternal social class $\left(r_{\mathrm{s}}=0.32, \mathrm{p}<0.001\right)$, maternal social class $\left(r_{\mathrm{s}}=0.30, \mathrm{p}<0.001\right)$, and parental education $\left(r_{s}=0.27, \mathrm{p}<0.001\right)$. Participants with lower affluence scores were more likely to have parents in manual occupations, while those with higher scores were more likely to have parents in professional and executive jobs, and this applied both to the fathers' and the mothers' occupations.

External validity was also evaluated by testing whether children whose postcodes indicated that they came from an area of greater socioeconomic deprivation reported lower levels of affluence. Townsend Index scores for the area of residence show a strong association with affluence scores (see fig 1), with a correlation of $r=-0.42, p<0.01$ between the HASC score and the Townsend Index.

Finally, we examined completion rates for data on parental education, occupation, and postcode in relation to HASC scores. The numbers of participants in each affluence group who had no parental occupational information available, either because they did not live with their mother or father, they did not complete the item, they gave occupation data that

Table 3 Percentages and (n) of parents in each occupational class or with missing data in relation to affluence scores (row percentages)

\begin{tabular}{|c|c|c|c|c|c|c|c|c|c|c|}
\hline & \multicolumn{10}{|c|}{ Paternal occupation class } \\
\hline & I $n=172$ & II $n=310$ & IIIn $n=75$ & IIIm $n=347$ & IV $n=77$ & $V n=15$ & $\begin{array}{l}\text { Total valid } \\
\mathrm{n}=996\end{array}$ & $\begin{array}{l}\text { Unemployed } \\
n=122\end{array}$ & $\begin{array}{l}\text { Missing } \\
\text { description } \\
\mathrm{n}=298\end{array}$ & $\begin{array}{l}\text { Does not } \\
\text { live with } \\
\text { father } \\
n=408\end{array}$ \\
\hline \multicolumn{11}{|l|}{ Affluence score } \\
\hline $0,1,2 n=387$ & $0.8(3)$ & $3.4(13)$ & $1.0(4)$ & $11.1(43)$ & $4.4(17)$ & $1.6(6)$ & $22.3(86)$ & $16.3(63)$ & $17.6(68)$ & $43.9(170)$ \\
\hline $3 n=370$ & $4.6(17)$ & $12.4(46)$ & $2.7(10)$ & $22.4(83)$ & $6.2(23)$ & $0.5(2)$ & 48.8 (181) & $8.9(33)$ & $17.0(63)$ & $25.1(93)$ \\
\hline $4 n=559$ & 9.7 (54) & $15.9(89)$ & $5.7(32)$ & $22.5(126)$ & $3.8(21)$ & $0.9(5)$ & $58.5(327)$ & $3.2(18)$ & $18.4(103)$ & $19.9(111)$ \\
\hline \multirow[t]{3}{*}{$5 n=508$} & $19.3(98)$ & $31.9(162)$ & $5.7(29)$ & $18.7(95)$ & $3.1(16)$ & $0.4(2)$ & $79.1(402)$ & $1.6(8)$ & $12.6(64)$ & $6.7(34)$ \\
\hline & \multicolumn{10}{|c|}{ Maternal occupation class } \\
\hline & $\mathrm{I} n=32$ & II $n=364$ & IIIn $n=247$ & $\mathrm{IIIm} n=124$ & $\mathrm{IV} n=156$ & $V n=88$ & $\begin{array}{l}\text { Total valid } \\
\mathrm{n}=1011\end{array}$ & $\begin{array}{l}\text { Unemployed } \\
n=409\end{array}$ & $\begin{array}{l}\text { Missing } \\
\text { description } \\
\mathrm{n}=289\end{array}$ & $\begin{array}{l}\text { Does not } \\
\text { live with } \\
\text { mother } \\
n=115\end{array}$ \\
\hline \multicolumn{11}{|l|}{ Affluence score } \\
\hline $0,1,2 n=387$ & $0.3(1)$ & $4.7(18)$ & 4.9 (19) & $5.9(23)$ & $7.8(30)$ & $7.0(27)$ & $30.6(118)$ & $43.2(167)$ & $18.1(70)$ & $8.3(32)$ \\
\hline $3 n=370$ & $1.9(7)$ & $14.9(55)$ & $12.7(47)$ & $8.9(33)$ & $9.7(36)$ & $6.5(24)$ & $54.6(202)$ & $23.8(88)$ & $14.6(54)$ & $7.0(26)$ \\
\hline $4 n=559$ & $1.6(9)$ & $20.8(116)$ & $15.2(85)$ & $8.2(46)$ & $9.7(54)$ & $4.3(24)$ & 59.8 (334) & $15.0(84)$ & $17.5(98)$ & $7.7(43)$ \\
\hline $5 n=508$ & $3.0(15)$ & $34.4(175)$ & $18.9(96)$ & $4.3(22)$ & $7.1(36)$ & 2.6 (13) & $70.3(357)$ & $13.8(70)$ & $13.2(67)$ & $2.8(14)$ \\
\hline
\end{tabular}




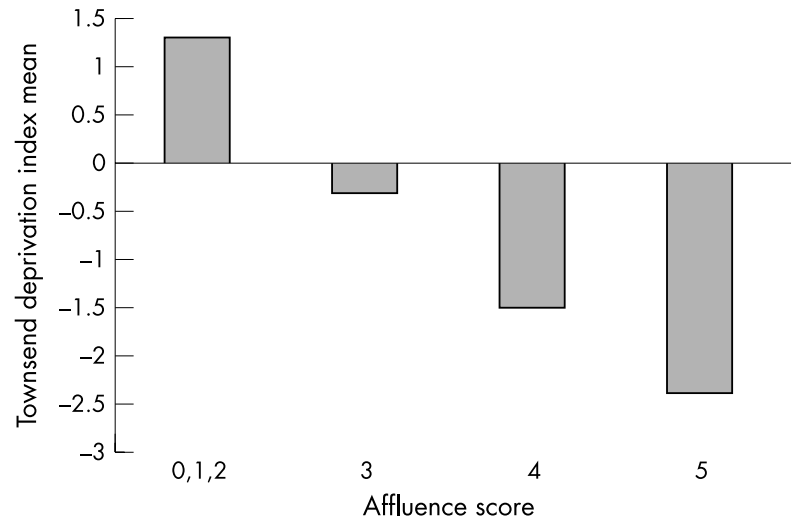

Figure 1 Home affluence scale compared to Townsend Material Deprivation Index.

could not be coded for occupational class, or their parents were not in paid employment, are shown in the last three columns of table 3. The results indicate that substantial bias would be introduced if occupational data were used, as students with lower scores on the affluence scale were much more likely to have missing data because of parental unemployment, parental absence, and uncodeable responses. Table 4 shows the odds ratios for missing information in relation to affluence group, using the highest affluence level as being the index category. The odds of having missing data for paternal occupational class, maternal occupational class, parental education, and postcode were significant at each level, and graded across HASC scores.

\section{DISCUSSION}

The aim of this paper was to consider the internal reliability and external validity of an affluence scale derived from adolescents' reports on material conditions in the home as a measure of the SES of the family. A review of existing research highlighted the difficulties of obtaining information on traditional SES markers (education, occupation, and income) from adolescents, and presented some evidence that markers of material circumstances might offer a useful alternative. The results of this study confirmed the comparatively poor completion rates for questions on parental education and occupation, and showed that material deprivation items have higher completion rates. Comparing results across schools with different average levels of pupil deprivation highlighted the fact that children with poorer material circumstances are less likely to be able to report on parental education and occupation. In contrast completion rates for most of the material markers did not vary by school type. Age was not found to affect completion rates in this sample, although this may be a result of the narrow age range of participants.

The external validity of a scale derived from adding the individual deprivation markers was assessed by examining associations between HASC scores and either student reported indices of SES (parental education and occupation), or objective markers of the socioeconomic environment (Townsend

\section{Key points}

- Adolescents are poor at responding to questions on parental education and occupation, and those from poorer backgrounds have particularly high levels of missing data.

- We developed a scale based on material items (the Home Affluence Scale) that had adequate internal reliability, good external validity, and shows less bias in completion.

- The home affluence scale may provide a useful alternative method for assessing SES in adolescents.

Index scores). The associations were all highly statistically significant and indicated a modest level of association, suggesting that as well as limiting the completion bias, HASC scores offer a viable substitute for occupational or educational data where the latter are difficult to obtain. When we take account of the multidimensional nature of SES, there is inevitably going to be a limit to the magnitude of associations between different indices of SES-as they are not simply alternative measures of the same underlying variable (see below). The HASC score might be expected to be most closely associated with parental income, which was not assessed in this study.

In the case of the association with the Townsend scale, given that an enumeration district is determined largely by political rather than social factors, that there is substantial variation within areas, and that area characteristics can change over time, the maximum expected association will be limited. One recent study using a large adult sample in the UK reported a correlation of 0.40 between postcode estimates of household income and individually reported income. ${ }^{15} \mathrm{~A}$ second study ${ }^{16}$ reported a correlation of -0.44 between the Carstairs Index (a deprivation measure derived from census data) at the enumeration district level and self reported household income for 2175 people in Glasgow. The correlation found in the present study $(r=-0.42)$ is, therefore, of a similar magnitude to that reported elsewhere.

Assessing the internal reliability probably raises more questions than it answers. If the affluence items are assumed to be indicators of some underlying (latent) construct (for example, material conditions), then we should expect them to show moderate levels of intercorrelation, and the resultant scale should have a reasonably high internal consistency. However, it should be noted that given the restricted range of the variables included in the correlations (for example, car ownership ranges from $0-2$, housing tenure, computer and free school meals range from $0-1)$ the coefficient is consequently reduced. ${ }^{17}$ The present results indicate that, at least for the items used in this study, and with this sample, there is comparatively low shared variance (less than 5\%), suggesting the items are more independent than is consistent with the idea of a single underlying construct. Future research could usefully explore the structure of material markers on the basis of this kind of conceptualisation. It would be desirable to use a larger number of material measures, and specifically test the unidimensional versus multidimensional structure that emerges from the patterning of results.

Table 4 Odds of missing data [with 95\% confidence intervals] on other SES markers in relation to scores on the home affluence scale

\begin{tabular}{lllll}
\hline Affluence group & $\begin{array}{l}\text { Odds of missing paternal } \\
\text { occupational class }\end{array}$ & $\begin{array}{l}\text { Odds of missing maternal } \\
\text { occupational class }\end{array}$ & $\begin{array}{l}\text { Odds of missing parental } \\
\text { education }\end{array}$ & Odds of missing post code \\
\hline $0,1,2$ & $13.3[9.6$ to 18.3$]$ & $5.4[4.0$ to 7.2$]$ & $3.8[2.8$ to 5.3$]$ & $4.7[3.0$ to 7.4$]$ \\
3 & $4.0[2.9$ to 5.3$]$ & $2.0[1.5$ to 2.6$]$ & $2.1[1.6$ to 3.1$]$ & $2.5[1.5$ to 4.0$]$ \\
4 & $2.7[2.0$ to 3.5$]$ & $1.6[1.2$ to 2.0$]$ & $1.9[1.4$ to 2.6$]$ & $1.3[0.8$ to 2.2$]$ \\
5 & 1.00 & 1.00 & 1.00 & 1.00 \\
\hline
\end{tabular}


An alternative conceptualisation of indicators of material disadvantage is that they represent a set of potentially independent exposures (albeit in contemporary Britain they may be correlated). Adding them together quantifies the number of adverse exposures that the individual has experienced-much like adding an array of biological and genetic risk factors to determine cardiovascular risk. This is in line with some current conceptualisations of material deprivation, which point to the very real adversities that are linked with the individual exposures. For example, rented housing produces insecurity of tenure, a higher likelihood of having to move home, and exclusion from the wealth gain associated with rising house values; lack of a car limits access to leisure time activities and increases exposure to risk of crime on late night public transport, etc. On this model, the extent of item intercorrelation is not critical to the validity of the scale. However, other factors such as whether the most important exposures have been included, or whether individual exposures might relate differently to particular health outcomes, become much more significant.

The specific items included in the HASC require further discussion. The fact that car ownership contributes up to two points in the HASC compared with other items that contribute just one point means that the scale is inevitably weighted towards this item. High levels of car ownership in British families meant that restriction to a dichotomous response (car ownership versus non-car ownership) would have considerably reduced the discriminatory power of the item. The inclusion of eligibility for free school meals has benefits and drawbacks. It is directly linked to family income and is a benefit that is administered through adolescents themselves, so that they are likely to be aware of it. The inclusion of this item, however, means that the HASC is primarily applicable to British adolescents, although researchers wishing to use the scale elsewhere may be able to replace this item with a local benefit. Studies wishing to use material indicators should consider that the sociocultural significance of some of the items may vary crossculturally, and even from region to region, so comparisons between studies should be made with caution. The cultural specificity of some of the items also means that the scale may require adaptation when used outside the United Kingdom.

The appropriate measurement of SES in adolescents has not been fully addressed in the literature. Evidence suggests that traditional measures of adolescent SES, such as parental occupation and education, suffer from poor completion rates and that using traditional markers selectively excludes students from less affluent families. Material markers of home affluence have the advantage of much higher completion rates and show little evidence of completion bias. The home affluence scale created in this study was found to have adequate internal reliability and substantial external validity when compared with parental education and occupation (where available) and area based deprivation scores. This approach does not replace traditional measures of occupation and education, but it adds to the repertoire of approaches available to researchers interested in assessing SES in adolescents.

\section{Authors' affiliations}

J Wardle, K Robb, F Johnson, ICRF Health Behaviour Unit, University College London, UK

Funding: this work was supported by a grant from the Economic and Social Research Council as part of the Health Variations Programme.

Conflicts of interest: none.

\section{REFERENCES}

1 Petridou E, Zavitsanos X, Dessypris N, et al. Adolescents in high-risk trajectory: clustering of risky behavior and the origins of socioeconomic health differentials. Prev Med 1997:26:215-19.

2 Tuinstra J, Groothoff JW, van den Heuvel WJ, et al. Socio-economic differences in health risk behavior in adolescence: do they exist? Soc Sci Med 1998;47:67-74.

3 Liberatos P, Link BG, Kelsey JL. The measurement of social class in epidemiology. Epidemiol Rev 1988;10:87-121.

4 Ostrove JM, Adler NE. Socioeconomic status and health. Current Opinion in Psychiatry 1998;11:649-53.

5 Goodman E. The role of socioeconomic status gradients in explaining differences in US adolescents' health. Am J Public Health 1999:89:1522-8

6 Lien N, Friestad C, Klepp KI. Adolescents' proxy reports of parents' socioeconomic status: How valid are they? J Epidemiol Community Health 2001;55:731-7.

7 West $\mathbf{P}$, Sweeting $H$, Speed $E$. We really do know what you do: a comparison of reports from 11 year olds and their parents in respect of parental economic activity and occupation. Sociology 2001;35:539-59.

8 Abramson JH, Gofin R, Habib J, et al. Indicators of social class. A comparative appraisal of measures for use in epidemiological studies. Soc Sci Med 1982;16:1739-46.

9 Baker D, Taylor H, The Alspac Survey Team. The relationship between condition-specific morbidity, social support and material deprivation in pregnancy and early motherhood. Soc Sci Med 1997;45:1325-36.

10 Bobak M, Hertzman C, Skodova Z, et al. Socioeconomic status and cardiovascular risk factors in the Czech Republic. Int J Epidemiol 1999;28:46-52.

11 Currie CE, Elton RA, Todd J, et al. Indicators of socioeconomic status for adolescents: the WHO Health Behaviour in School-aged Children Survey. Health Educ Res 1997;12:385-97.

12 OPCS. Standard Occupational Classification. London: HMSO, 1991.

13 Crown Copyright. The 1991 Census. ESRC purchase, 1991.

14 Townsend P, Phillimore P, Beattie A. Health and deprivation: inequality and the North. Kent: Croom Helm, 1988.

15 Danesh J, Gault S, Semmence J, et al. Postcodes as useful markers of social class: population based study in 26000 British households. BM 1999;318:843-4

16 McLoone P, Ellaway A. Postcodes don't indicate individuals' social class. BM 1999;319:1003-4.

17 Howell DC. Statistical methods for psychology. Belmont: Wadsworth Publishing Company, 1997 